\title{
Effect of Self-Care Education on the Illness Perception in Patients With Hemodialysis: A Randomized Control Trial
}

\author{
Samira Tabiban', Mohammad Ali Soleimani², Human Bakhshandeh ${ }^{3}$, Marzieh Asghari ${ }^{*}$ \\ 1. Assistant Professor, Department of Nephrology, Heart Research Center of Shahid Rajaee, Tehran, Iran \\ 2. Associate Professor, Social Determinants of Health Research Center, Qazvin University of Medical \\ Sciences, Qazvin, Iran \\ 3. Associate Professor, Department of Epidemiology, Heart Research Center of Shahid Rajaee, Tehran, \\ Iran \\ 4. MSc Student in Nursing, Heart Research Center of Shahid Rajaee, Tehran, Iran
}

\begin{tabular}{lll}
\hline Article Info & Abstract \\
\hline
\end{tabular}

Received: $\quad$ 2017/08/02 Accepted: 2017/09/02

Published Online: 2019/05/22

DOI: 10.30699/sjhnmf.27.2.73

Original Article

Use your device to scan and read the article online

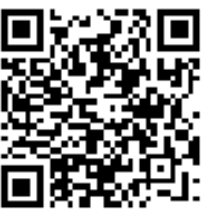

Introduction: The results of studies have shown that inadequate awareness and self-care of patients with chronic renal failure, leads to an incorrect illness perception in these patients. Considering the importance of this issue, this study aimed to investigate the effect of self-care education in patients undergoing hemodialysis.

Methods: This was a simple randomized clinical trial. The statistical society of the study consisted of 120 patients undergoing hemodialysis in dialysis department of Bu-Ali Sinai Hospital in Qazvin from December 2016 to February 2017. The samples were assigned randomly to two groups of control (routine care) and intervention (illness perception intervention). Both groups completed the demographic information questionnaire, illness perception questionnaire before the intervention. The intervention group received self-care education based on illness perception in the patient's bedside and before initiation of dialysis in 3 sessions of 30 minutes. A training booklet was also given at the second session of the patient's delivery, which was provided by the researcher and under the supervision of the professors. Four weeks later, the questionnaire of illness perception was completed by both groups. Data were analyzed using descriptive and analytic statistical tools in SPSS 20.

Results: The results of this study showed that there was not a significant difference between the two groups in terms of demographic information, except for the duration of dialysis $(P<0.014)$. The ANOVA test results showed a significant difference in terms of patient's illness perception between the intervention and control group $\left(\mathrm{F}_{11}\right.$, $\left.{ }_{112)}=13.88, P<0.001\right)$.

Conclusion: Self-care educational intervention based on illness perception increased the perception of the disease in hemodialysis patients.

Keywords: Illness Perception, Self-Care Education, Hemodialysis 


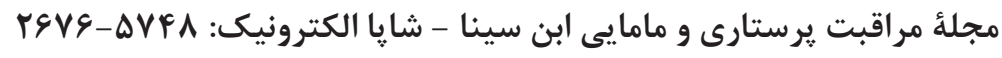

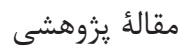

بررسى تأثير آموزش خودمراقبتى بر درك از بيمارى در بيماران تحت درمان با همودياليز:

$$
\text { يك كار آزمايى بالينى }
$$

سمير اطبيبان'، محمدعلى سليمانى"، هومن بخشنده"، مرضيه اصغرى"

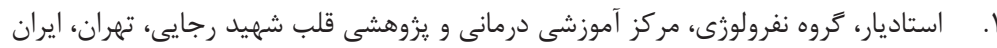

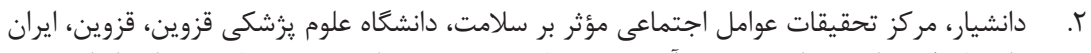

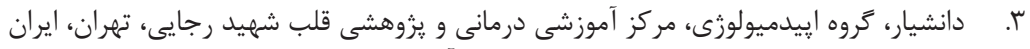

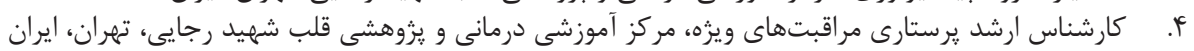

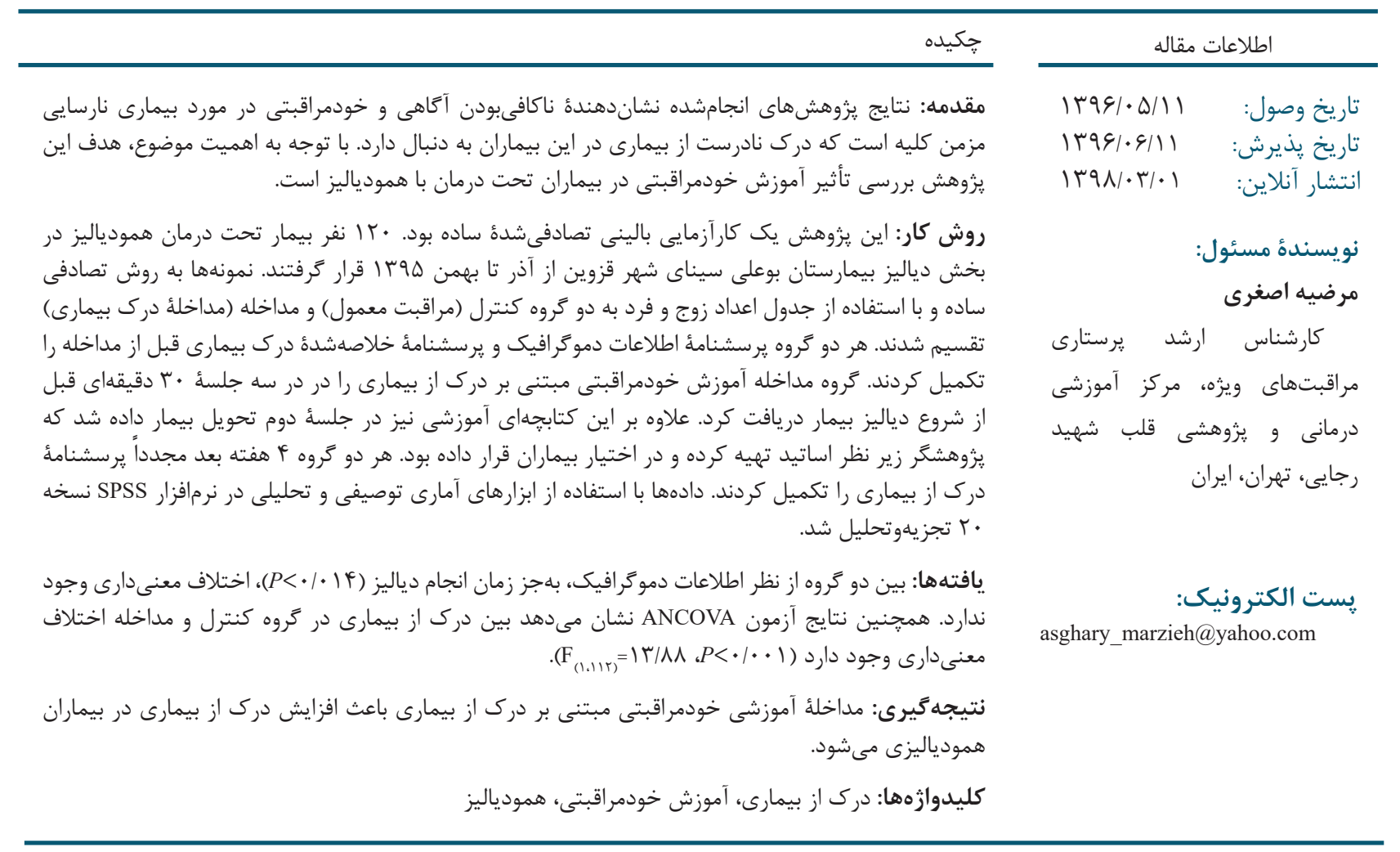

مقلم هـ

اين بيماران مىشود؛ در حالى كه فقط // ادرصد از جمعيت

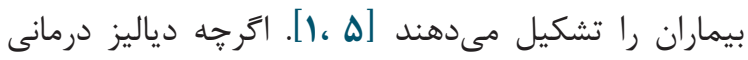
براى بيماران است، ولى اين بيماران در طولانىمدت دهين دهار

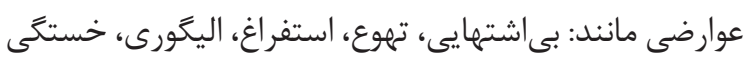

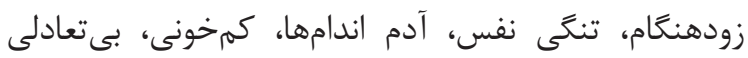

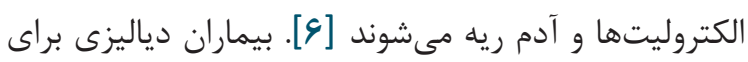
درمان بايد به جهار عامل اصلى حضور در جلسات دياليز،

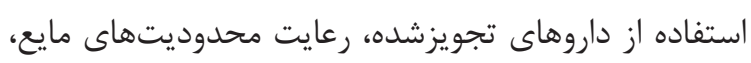

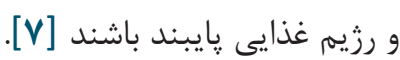

طبق يزوهشهاى انجامشده آمار بالايى از يايبندنبودن

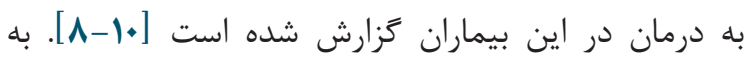

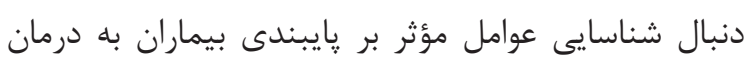

نارسايى مزمن كليه زمانى اتفاق مىافتد كه كليهها نتوانند

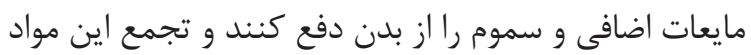
در بدن براى ادامٔٔ حيات فرد مضر است [1]] نياز به درمان

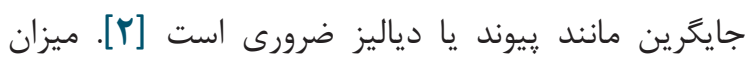
افزايش افراد مبتلا به نارسايى مزمن كليه، كه نياز به دياليز

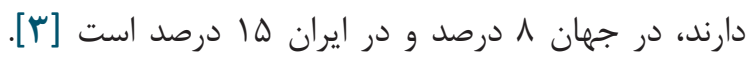

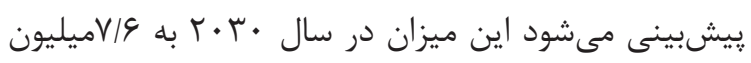

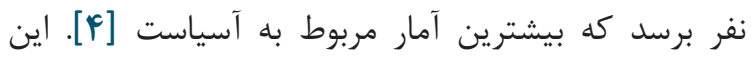
بيماران اكثراً افراد فقير جامعه هستند و نسبت بـن به جمعيت

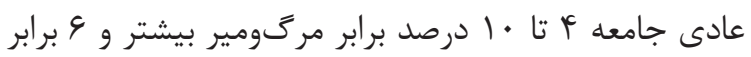

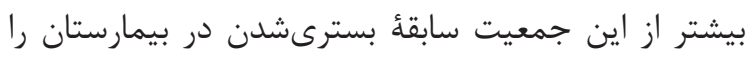

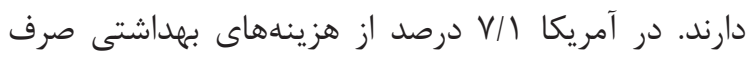


بهداشتى بايد سطح آكاهى، درك از بيمارى و پايبندى به

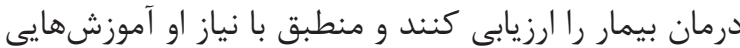

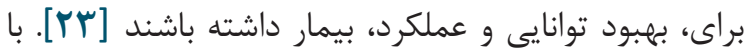
توجه به اهميت موضوع آموزش، به عنوان تشخيصى مهرم كه

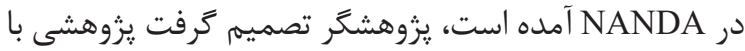

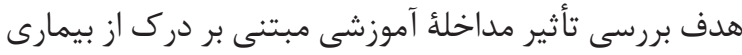
در بيماران تحت درمان با همودياليز انجام دهد.

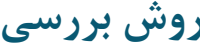

اين يزوهش كارآزمايى بالينى تصادفىشده و جامعهُ يزوهش بيماران مبتلا به نارسايى مزمن كليه، كه در بيمارستان بوعلى سيناى شهر قزوين در سال هو همودياليز مىشدند،

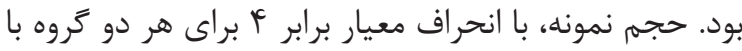

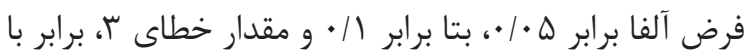

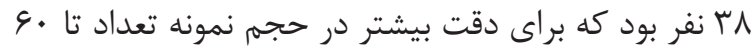
نفر در هر تروه افزايش داده شد.

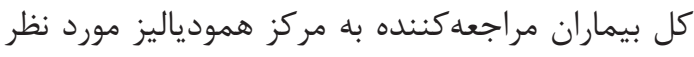

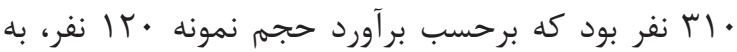
روش تصادفى ساده، انتخاب شدند. به اين صورت كه ليست بيماران مراجعهكنده به مركز دياليز به عنوان جهارجوب لهاب

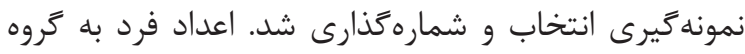
مداخله و اعداد زوج به كَروه كنترل تقسيم شد (نمودار

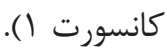

معيار ورود به يزوهش شامل داشتن سن بالاى \1اسال،

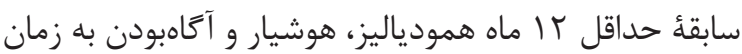
و مكان، تمايل به شركت در يزوهش، حداقل دو جلسه همودياليز در هفته، توانايى تكميل : يرسشنامه و شركت

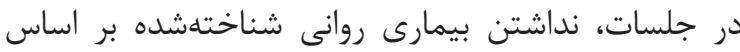

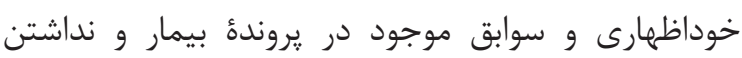

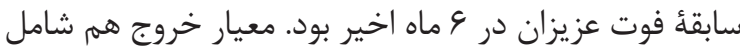
بى حالى و ضعف يا كاهش سطح هوشيارى، تمايلنداشتن به

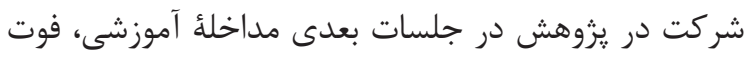

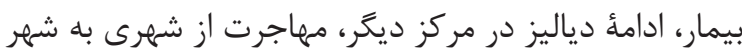
ديكر و هر علتى كه باعث خروج بيمار از يزوهش بود (نمودار

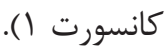

ابزار كردآورى دادهها شامل مشخصات دموكر افيك (سن،

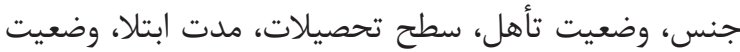
اقتصادى، منبع اصلى درآمد، مدت زمان تشخيص بيمارى، تعداد دفعات انجام دياليز در هفته، حضور در فعاليتهاى
به درك از بيمارى اشاره شده است [V] درك از بيمارى در سالهاى اخير توجه زيادى به خود جلب كرده است.

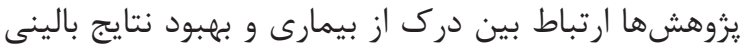

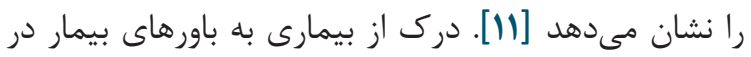

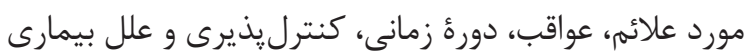
اشاره دارد [1/[]] در رويكرد بيمارمحور برداشت بيماران دياليزى از بيمارى و درمان متفاوت است و درك از بيمارى،

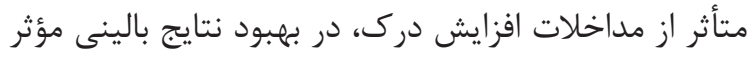

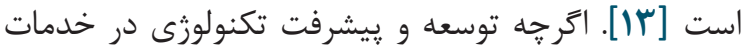

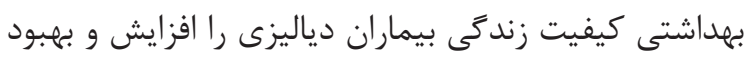
داده است، ولى بيشتر بيماران درك نادرستى از بهيبوني

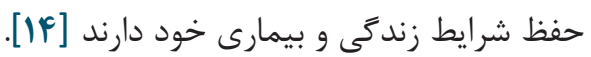

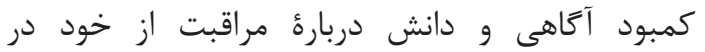
زمينههاى رزيم غذايى، مصرف مايعات و مراقبت از مسير

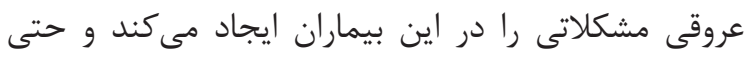

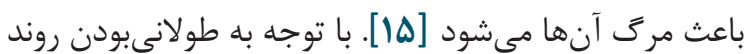
درمان بيماران دياليزى نياز به تغيير در سبك زندكى خود آندا

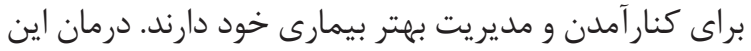
بيماران بدون مشاركت خود بيمار و فعاليتهاى خودمراقبتى نتايج مطلوب راندارد [19]. برنامةٔ خودمدير يتى مفهوم مهمى بدى

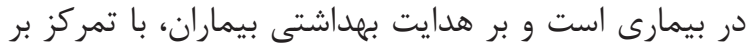

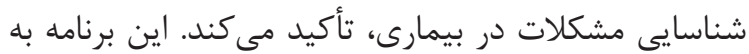

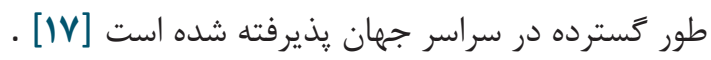

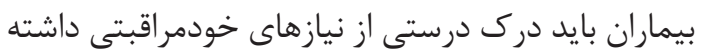

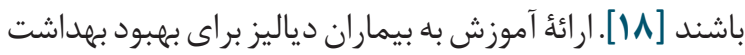

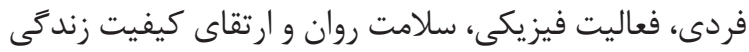

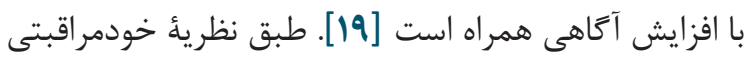
اورم افراد بايد متكى به خود و مسئول مراقبت از خود باشند. مراقبت از خود شكلى توسعهيافته و بيشرفته از ييشخيرى و إنى درمان است و يك فرد براى جلوكيرى از مشكلات بهداشتى ترانى

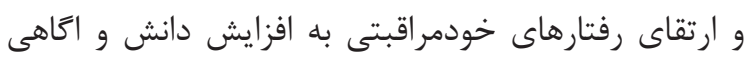
نياز دارد [•r]. فعاليتهاى خودمراقبتى در بيماران دياليزى نقش مهمى در استقلال اين بيماران دارد [آr]. آموزش به ديه

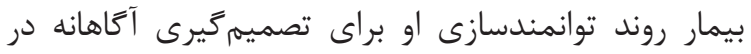

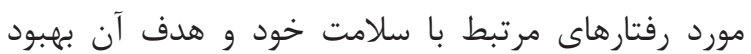
سلامت با تشويق و انطباق با رزيمهاى درمانى و ارتقاى شيوه

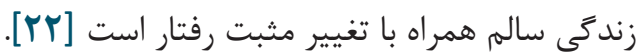

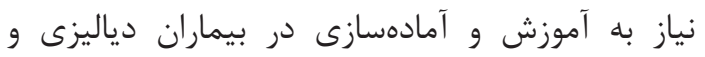

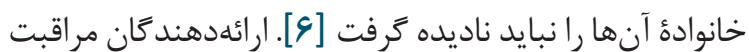




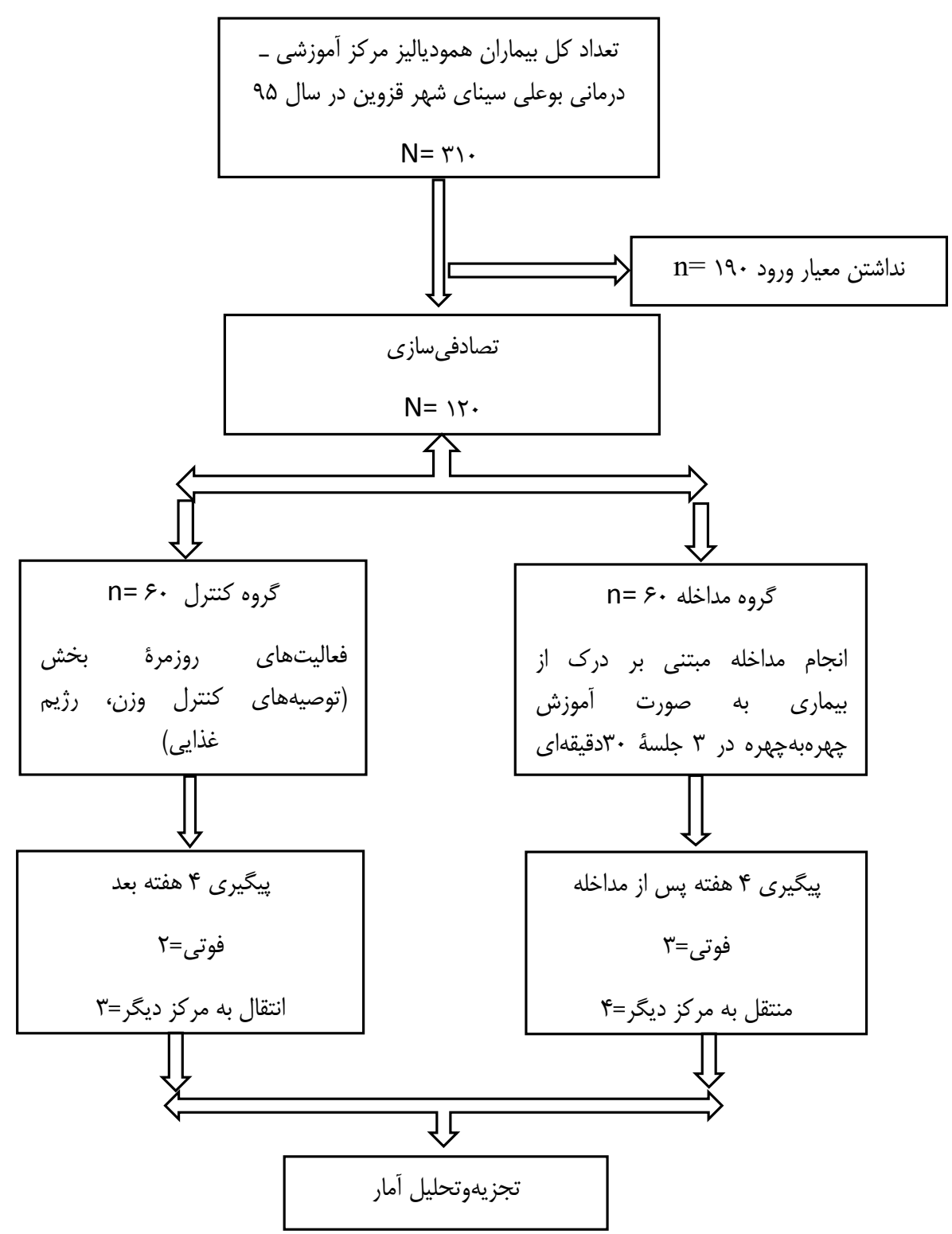

نمودار كانسورت ا. روند انتخاب بيماران در يزوهش RCT

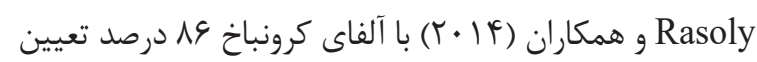

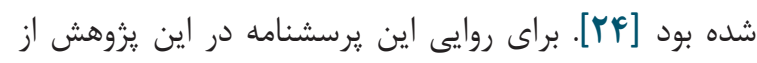

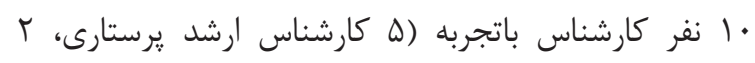

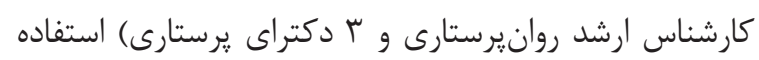

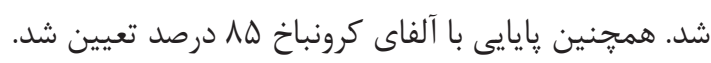

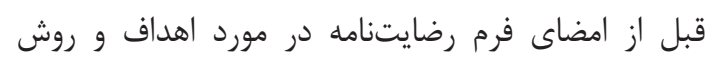

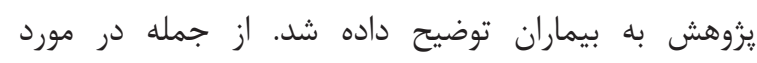

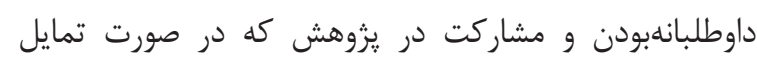

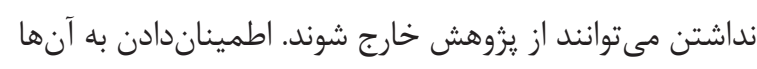

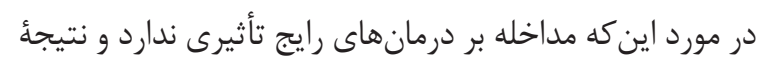

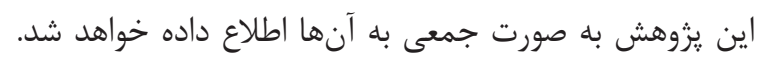

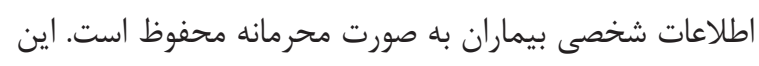

اجتماعى و ميزان حمايت اجتماعى) بود.

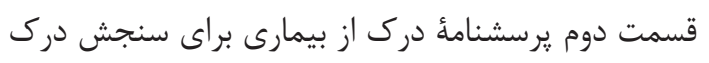

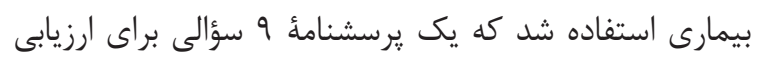

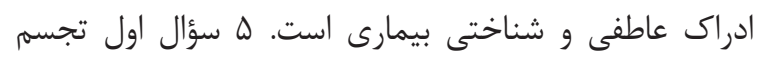

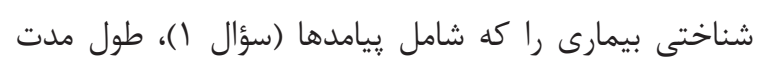

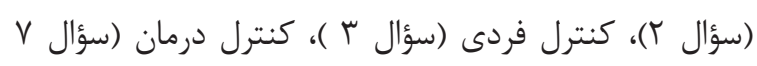

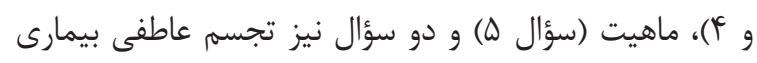

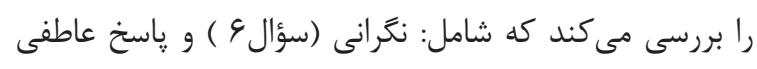

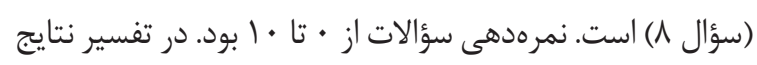

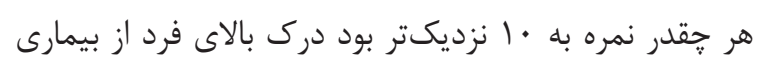

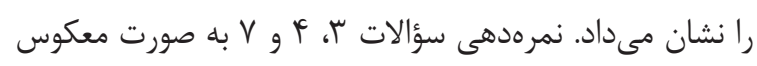

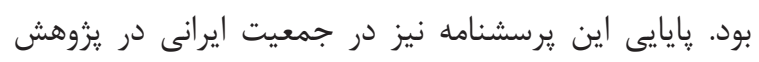


بر برى شد. دادهها در نرمافزار SPSS نسخه ·r تجزياهوتحليل شد. براى آمارهاى توصيفى (تعداد، ميانگين، انحراف معيار) و آزمون

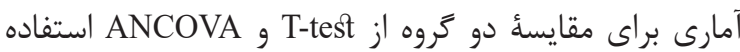
شد. سطح معنى دارى ه •|•=P در نظر گرفته و براى توصيف نتايج از شاخصهاى آمارى، جدولها، نمودارها استفاده شده

كافتهها

جدول ا نشان مىدهد ميانگين سنى // اצعال (اس/ | | =|نحراف معيار) و محدوده سنى در دو گروه 9 ( تا \&1 سال بود. همجنين بيشتر بيماران مرد (T/ ه د درصد) وץ نفر و از نظر وضعيت تأهل

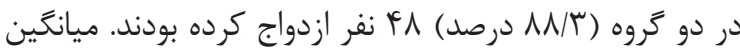

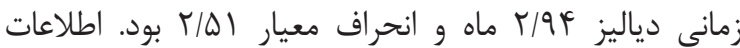
دموكرافيك در دو گروه نشان مىدهد اختلاف معنىدارى از نظر سن، جنس، وضعيت تأهل و سطح سواد وجود ندارد، اما از نظر مدت زمان انجام دياليز در گروه كنترل (I/9)

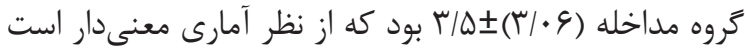

$$
\text { ( ) (جدول) }(P<\cdot|\cdot| c)
$$

نتايج نشان مىدهد بيشترين ميزان تحصيلات مربوط به

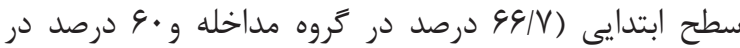
كروه كنترل) بود و اكثر نمونهها وضعيت اقتصادى متوسط (مه درصد) داشتند، اما از نظر منبع درآمد بيشترين آمار مربوط به

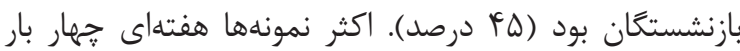
دياليز مىشدند. نتايج آمارى نشان مىدهد بيماران هر دو گروها خيلى كم در فعاليتهاى اجتماعى از قبيل: ييادهروى با دوستان، حضور در مجالس مختلف، برگزارى مجالس شركت مى كنند. در

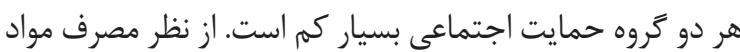

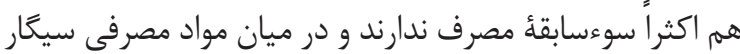
بيشترين آمار (سا درصد) را دارد. بيشتر نمونهها سابقهُ بيمارى

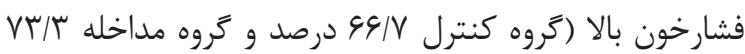
درصد)، بيمارى ديابت (گروه مداخله فه درصد و گروه مداخله

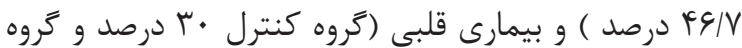
مداخله Q ا درصد) داشتند (جدول (). نتايج حاصل از يافتههاى دو گروه در جدول r نشان مىدهد كه تفاوت مشهودى در

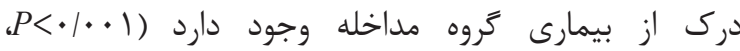

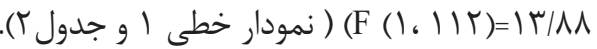

يزوهش در كميتهٔ اخلاق و يزوهش مركز قلب شهيد رجايى تصويب (Rhc.ac.ir.1395.24) و در مركز كارآزمايى بالينى با كد IRCT2016103130609N1 يس از تكميل فرم رضايتنامه هر دو گروه پرسشنامههاى

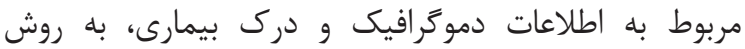
مصاحبه، را تكميل كردند. يزووهشگر، به علت زياد بودن سؤالات

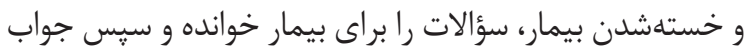

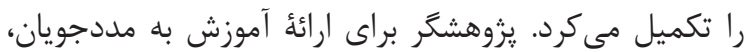

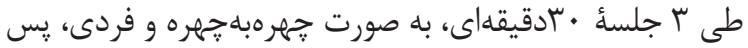
از كسب اجازه از بيمار، مداخلهُ درك از بيمارى را شروع مى كرد. در جلسأ اول آموزش بر اساس ه بعد درك بيمارى و همجنين

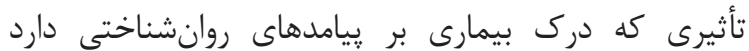
״ايهريزى شده بود. اين ابعاد عبارت بود از: ا. ماهيت بيمارى (برجسب و علائم مربوط به بيمارى مانند: خستگى، ضعف،

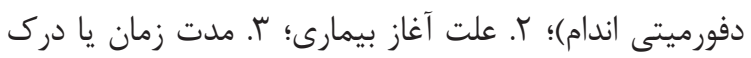

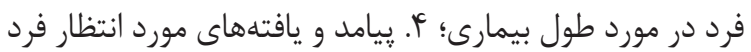
از بيمارى؛ ه. مؤثربودن كنترل، درمان و بهبود بيمارى. براى مداخله درك از بيمارى از تكنيكهاى خودكنترلى، تشويق كلامى و طراحى هدف (مثل افزايش وزن بين جلسات همودياليز)، بازخورد و ارزيابى رفتارها، استفاده از تجربيات افراد موفق در زمينه بيمارى استفاده شد. به بيمار كفته شد كه يزوهشگر دو ماه در بخش دياليز در تمامى شيفتها حضور

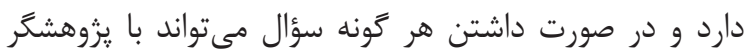
مطرح كند.

در جلسأ دوم يس از مرور آموزشهاى جلسهُ قبل از بيمار خواسته شد تا از احساسات و ابهامات بيمارى خود صحبت كند.

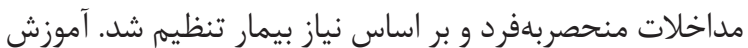
براى تغيير درك نادرست، كه ممكن بود نسبت به بيمارى داشته باشد، طراحى شد. به بيماران گَفته شد در صورتى كه

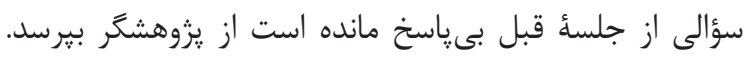

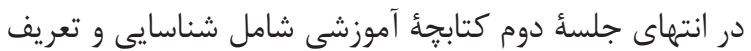
بيمارى، مواردى كه بيماران در رزيم غذايى بايد رعايت كنند،

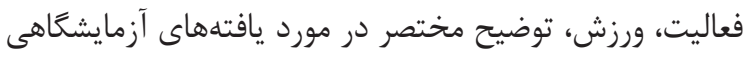
و توصيههاى روانشناسى در مورد اضطراب و اميد كه يثوهشگر زير نظر متخصصان در زمينأ يزوهش تهيه و تنظيم كرده بود در اختيار بيمار قرار گرفت. در جلسأُ سوم (ارزشيابى) از جلسأ قبل در مورد جلسهُ يايانى به بيمار اطلاع داده شده بود. ابتدا

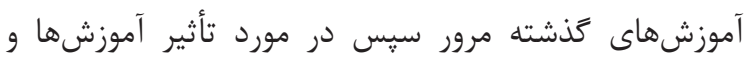
تجربيات جديد از بيمار سؤال و مشكلات و موانع براى هر بيمار 
جدول ا. توزيع فراوانى مشخصات فردى بيماران تحت همودياليز در دو گروه كنترل و مداخلئ مركز بوعلى سيناى شهر قزوين در سال هه؟1

\begin{tabular}{|c|c|c|c|c|}
\hline سطح معنىدارى & تعداد (درصد كنترل & تعداد (دره مداخله & \multicolumn{2}{|c|}{ مشخصات فردى } \\
\hline \multirow{2}{*}{$\cdot \mid \wedge \Delta r$} & rद(G•) & $r \Delta(\Delta \Lambda / \Psi)$ & 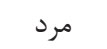 & \multirow[b]{2}{*}{ جنس } \\
\hline & $M F(Y \cdot)$ & $r \Delta(Y \backslash / V)$ & 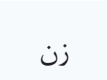 & \\
\hline \multirow{4}{*}{. IOHA } & $r(\Delta)$ & $\varphi(1 \cdot)$ & مجرد & \multirow{4}{*}{ وضعيت تأهل } \\
\hline & $\Delta \cdot(\Lambda r / r)$ & $\operatorname{EV}(\vee \wedge / \Psi)$ & متأهل & \\
\hline & $V(1) / V)$ & $\varphi(1 \cdot)$ & بيوه & \\
\hline & - & $I(1 / V)$ & جداشده & \\
\hline \multirow{3}{*}{ ודז/. } & $1 \wedge\left(\Gamma^{\prime}\right)$ & $\mid \Lambda(r \cdot)$ & بيسواد & \multirow{3}{*}{ تحصيلات } \\
\hline & $r \varphi(\varphi \cdot)$ & $f \cdot(\varepsilon q / V)$ & ابتدايى & \\
\hline & $q(1 \cdot)$ & $r(\Gamma / \Gamma)$ & دانشعاه & \\
\hline$\cdot / 4 \wedge \Delta$ & $q \mid / \cdot r(|F /| q)$ & $\Delta q / \backslash \wedge(\mid F / \Delta r)$ & & سن \\
\hline.$/ .1 \mathrm{f}$ & $T / \Gamma V(1 / 9)$ & $\Gamma / \Delta(\Psi / \cdot \varphi)$ & & مدت تشخيص دياليز \\
\hline
\end{tabular}

جدول r. توزيع فراوانى ميانكين و انحراف معيار متغير يزوهش قبل و بعد از آزمون در دو كروه كنترل و مداخله

\begin{tabular}{|c|c|c|c|c|}
\hline سطح معنادارى & اختلاف ميانكين & ميانكَين (انحراف معاخ ملهار) & ميانگين (انحراف معيار) & \multirow{3}{*}{ ثرى بيمارى } \\
\hline$-r / 9) ؛ \cdot / \cdot \Delta$ & $-r / \Delta \wedge(\& / \Lambda V)$ & $\Delta \varepsilon / \Upsilon q(\Gamma / \vee \wedge)$ & $\Delta r / q \vee(\xi / \cdots)$ & \\
\hline \multirow[t]{2}{*}{$-1 / \Delta T: \cdot / 1 T F$} & $-1 / \Delta \Delta(9 / 9 \cdot)$ & $\Delta T / V T(\xi / \mid F)$ & $\Delta / / 1 \%(\Delta / 9 \Lambda)$ & \\
\hline & & $\left|r / \Lambda \Lambda^{b}<\cdot / \cdot \cdot\right|$ & $r / A r^{\mathrm{a}} \cdot . / \cdot 11$ & سطح معنادارى بين كروهها \\
\hline
\end{tabular}

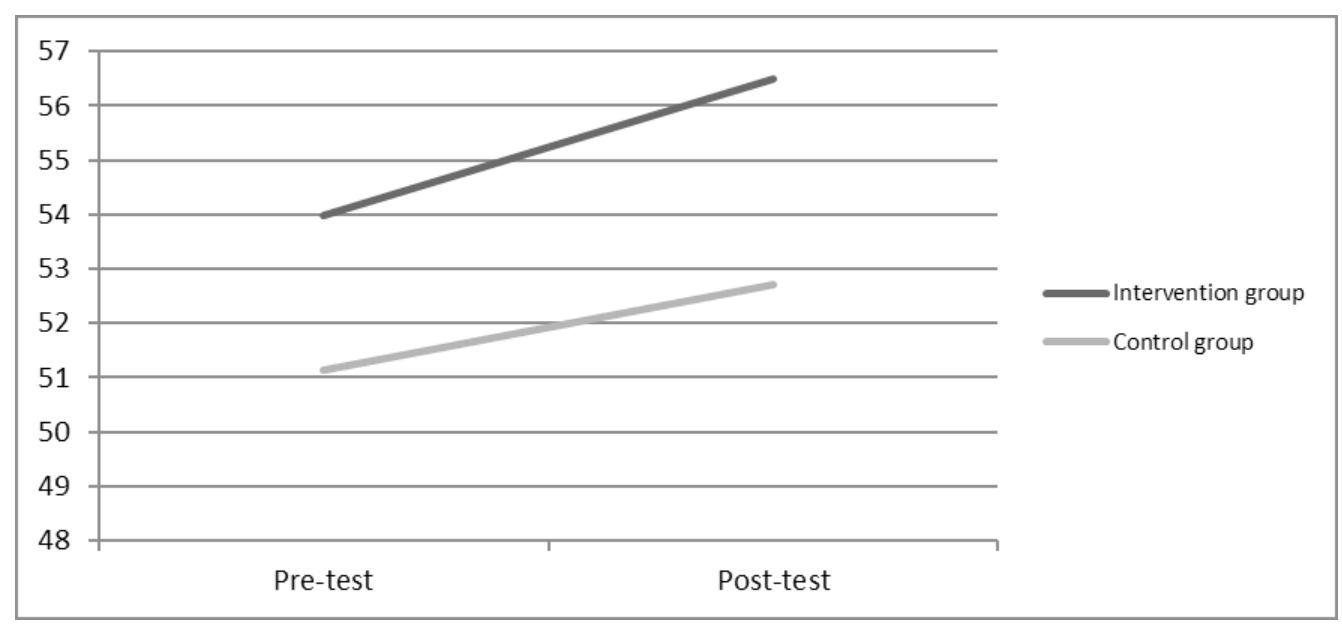

نمودار خطى ا. درك از بيمارى در دو عروه كنترل و مداخله قبل و بعد از آزمون 
بررسى كردند. نتايج ارتباط بين درك از بيمارى و صلاحيت

خودمراقبتى در اين بيماران را نشان مىدهد [TV] از محدوديتهاى اين يزوهش سروصداى موجود در بخش است كه در فرآيند آموزش بر بيمار تأثيركذار بود و توصيه مىشود در يزوهشهاى بعدى آموزش در محيطى

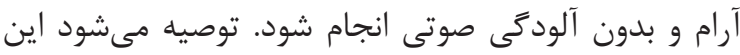
يُوهش بر ديكر بيمارىهاى مزمن مانند: بيماران قلبى، بيماران آسيب نخاعى و بيماران MS انجام شود.

\section{نتيجهل}

با توجه به اهميت افزايش آكاهى خودمراقبتى در بيماران و تأثيرى كه بر درك بيمارى در اين بيماران دارد توصيه

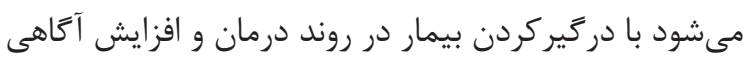
در زمينهٔ درى بيمارى شاهد كاهش ييامدهاى يرهزينه در در

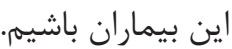

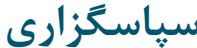

اين مقاله بخشى از קاياننامٔٔ كارشناسى ارشد مراقبت ويزه

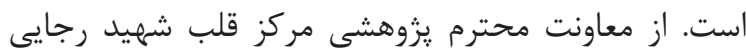

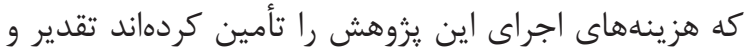
تشكر مى كنيم (Rhc.ac.ir.1395.24). همجنين از اساتيد و كاكنان محترم بخش دياليز بيمارستان بوعلى سيناى شهر

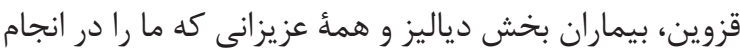
اين يزوهش يارى رساندهاند تقدير و تشكر مى كنيه.

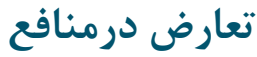

بين نويسندكان هيجَّونه تعارضى در منافع وجود ندارد.
هدف اين يزوهش افزايش درك از بيمارى در بيماران تحت درمان با همودياليز از طريق آموزش خودمراقبتى بود. نتايج نشان داد مداخلة افزايش آموزش خودمراقبتى مبتنى بر بر بران درك از بيمارى باعث افزايش درك از بيمارى در بيماران

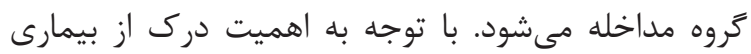

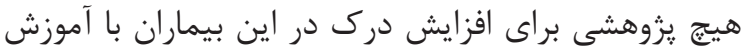

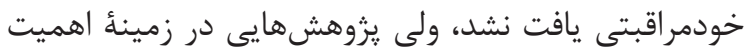
درك و خودمراقبتى در بيمارىهاى مزمن انجام شده است. نتايج :زوهش Park و همكاران (•l(Y)، كه با هدف تأثير برنامة آموزش خودمراقبتى در بيماران دياليزى به صورت

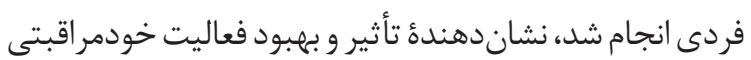

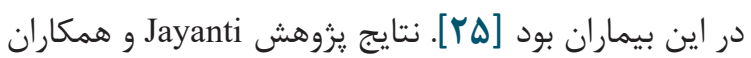

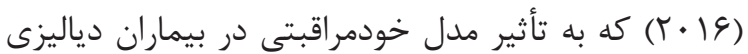
يرداختهاند، نشان مىدهد با افزايش درك بيمارى بيماران كنترل بيشترى بر دفعات دياليز، رعايت رزيم غذايى و مايعات

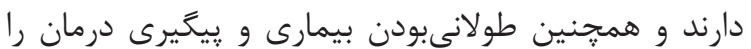

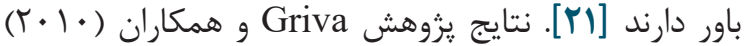

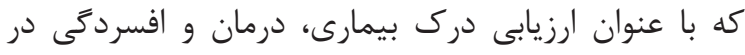

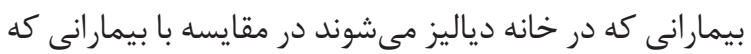
در بيمارستان دياليز مىشوند، نشان مى دهد مزاياى مراقبت از خود در دياليز به طور يكنواخت ظاهر نمىشود و تشخيص بيمارى عامل تعيين كننده در افسردىى و ييامدهاى بالينى

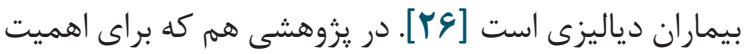
درك از بيمارى توسط Chilcot و همكاران (Y • (T) انجام

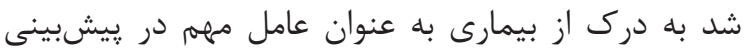

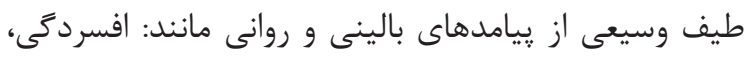
پايبندنبودن به درمان و حتى بقا اشاره شده است. طبق اين

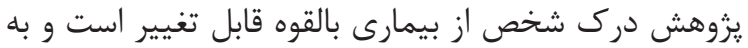
انجام مداخلات براى بهبود يُيامدهاى بالينى و روانى توصيه

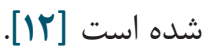

در يزوهش ديخرى كه توسط Choi و همكاران (T/ T) انجام شد به اهميت آموزش جهرهبهجهره، آكاهىدادن و ولان تأثيرات برنامة خودمراقبتى در بيماران با نارسايى مزمن كليه

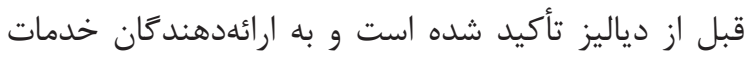

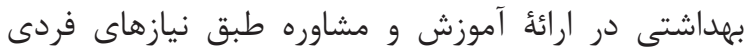

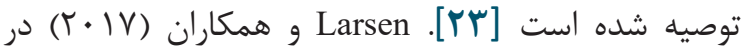
يزوهشى، بر بيماران يسوريازيس مبتلا به اختلال هيجانى،

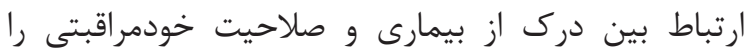




\section{References}

1. Gray KS, Cohen DE, Brunelli SM. In-center hemodialysis absenteeism: prevalence and association with outcomes. Clinico Economics and Outcomes Research. 2017; 9:307-315.

2. Hudson JL, Moss-Morris R, Game D, Carroll A, McCrone P, Hotopf $\mathrm{M}$, et al. Improving distress in dialysis (iDiD): a feasibility two-arm parallel randomised controlled trial of an online cognitive behavioural therapy intervention with and without therapist-led telephone support for psychological distress in patients undergoing haemodialysis. BMJ Open. 2016; 6(4):e011286.

3. Heidarzadeh $\mathrm{M}$, Atashpeikar S, Jalilazar $\mathrm{T}$. Relationship between Quality of life and self care ability in patients receiving hemodialysis. Iranian journal of nursing and midwifery research. 2010; $15(2)$.

4. Feng L, Jin AZ, Allen JC, Chow KY, Jafar TH. Timing of commencement of maintenance dialysis and mortality in young and older adults in Singapore. BMC nephrology. 2017;18(1):176.

5. Krumholz HM, Nuti SV, Downing NS, Normand S-LT, Wang Y. Mortality, hospitalizations , and expenditures for the Medicare population aged 65 years or older, 1999-2013. JAMA. 2015; 314(4):355-365.

6. Chutel P, Youtham PJ, Kumawat S. An Exploratory Study To Assess The Effectiveness Of Self Structured Module On Renal Care Among Staff Nurses Taking Care Of Patients Undergoing Dialysis In Medical Wards Of Tertiary Level Hospital In Indore. International Journal of Nursing and Medical Science (IJNMS). 2015; 4(3):419-439.

7. Kim Y, Evangelista LS. Relationship between illness perceptions, treatment adherence, and clinical outcomes in patients on maintenance hemodialysis. Nephrology nursing journal: journal of the American Nephrology Nurses' Association. 2010; 37(3):271.

8. Kutner NG, Zhang R, McClellan WM, Cole SA. Psychosocial predictors of non-compliance in haemodialysis and peritoneal dialysis patients. Nephrology Dialysis Transplantation. 2002; 17(1):93-9.

9. Lee S-h, Molassiotis A. Dietary and fluid compliance in Chinese hemodialysis patients. International journal of nursing studies. 2002; 39(7):695-704.

10. Durose CL, Holdsworth M, Watson V, Przygrodzka F. Knowledge of dietary restrictions and the medical consequences of noncompliance by patients on hemodialysis are not predictive

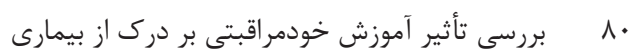

of dietary compliance. Journal of the American Dietetic Association. 2004; 104(1):35-41.

11. Parfeni M, Nistor I, Covic A. A systematic review regarding the association of illness perception and survival among end-stage renal disease patients. Nephrology Dialysis Transplantation. 2013; 28(10):2407-2414.

12. Chilcot J, editor The importance of illness perception in end-stage renal disease: associations with psychosocial and clinical outcomes. Seminars in dialysis; 2012: Wiley Online Library.

13. Jansen DL, Heijmans MJ, Rijken M, Spreeuwenberg P, Grootendorst DC, Dekker FW, et al. Illness perceptions and treatment perceptions of patients with chronic kidney disease: different phases, different perceptions? British journal of health psychology. 2013; 18(2):244-262.

14. Bae J, Park H, Kim S, Bang J. Factors influencing depression in patients with chronic renal failure. Journal of Korean Academy of Psychiatric and Mental Health Nursing. 2011; 20(3):261-270.

15. Klang B, Björvell H, Clyne N. Predialysis education helps patients choose dialysis modality and increases disease-specific knowledge. Journal of advanced nursing. 1999; 29(4):869876.

16. Cowen PS, Moorhead S. Current issues in nursing: Elsevier Health Sciences; 2014.

17. Lorig KR, Hurwicz M-L, Sobel D, Hobbs M, Ritter PL. A national dissemination of an evidence-based self-management program: a process evaluation study. Patient education and counseling. 2005; 59(1):69-79

18. Kallenbach JZ. Review of hemodialysis for nurses and dialysis personnel: Elsevier Health Sciences; 2015.

19. Ghadam MS, Poorgholami F, Jahromi ZB, Parandavar N, Kalani N, Rahmanian E. Effect of Self-Care Education by Face-to-Face Method on the Quality of Life in Hemodialysis Patients (Relying on Ferrans and Powers Questionnaire). Global journal of health science. 2016; 8(6):121.

20. Alligood MR .Nursing theorists and their work: Elsevier Health Sciences; 2014.

21. Jayanti A, Foden P, Wearden A, Mitra S. Illness Beliefs in End Stage Renal Disease and Associations with Self-Care Modality Choice. PloS one. 2016; 11(7):e0154299.

22. Bellamy R. An introduction to patient education: theory and practice. Medical teacher. 2004; 26(4):359-65.

23. Choi ES, Lee J. Effects of a face-to-face selfmanagement program on knowledge, self- 
care practice and kidney function in patients with chronic kidney disease before the renal replacement therapy. Journal of Korean Academy of Nursing. 2012; 42(7):1070-1078.

24. Seyyedrasoly A, Rahimi Z. Effect of Illness Perception Promoting Intervention on Quality of Life of Hemodialysis patients: a Clinical Trial. Preventive Care in Nursing \& amp; Midwifery Journal. 2014; 3(2):1-12.

25. Park H-M, Lee H-S. Effects of empowerment education program for hemodialysis patients on self-efficacy, self-care agency, self-care activities and physiologic parameters. The Korean Journal of Rehabilitation Nursing. 2010; 13(2):151-160.

26. Griva K, Davenport A, Harrison M, Newman S. An evaluation of illness, treatment perceptions, and depression in hospital-vs. home-based dialysis modalities. Journal of psychosomatic research. 2010; 69(4):363-370.

27. Larsen MH, Krogstad AL, Wahl AK. Alexithymia, Illness Perception and Selfmanagement Competency in Psoriasis. Acta dermato-venereologica. 2017. 